\title{
Una mala palabra. Sobre una polémica desconocida en torno a la Historia de la literatura argentina de Ricardo Rojas ${ }^{1}$
}

\author{
A bad word. On an unknown controversy around Ricardo Rojas's
} History of Argentine Literature

Silvia Tieffemberg

Universidad de Buenos Aires

Consejo Nacional de Investigaciones Científicas y Técnicas

silvia.tieffemberg@gmail.com

\section{Resumen}

El presente trabajo propone el análisis de la primera polémica en torno a la Historia de la literatura argentina (1917-1922) de Ricardo Rojas. Esta polémica, desconocida hasta el momento, se desarrolla entre Juan de la Cruz Puig y el propio Rojas a través de los artículos "Una afrenta y una falsedad" y "Una mala palabra", publicados en la revista Estudios en abril y mayo de 1918 respectivamente. El análisis contempla a sus protagonistas y el marco contextual que los albergó, en la perspectiva de lo que el crítico Jorge Panesi denomina "polémicas ocultas".

Palabras clave: Ricardo Rojas, Juan de la Cruz Puig, polémicas.

\section{Abstract}

This paper proposes the analysis of the first controversy over the History of the Argentine literature (1917-1922) of Ricardo Rojas. This controversy, unknown so far, develops between Rojas and Juan de la Cruz Puig through articles "An affront and a falsehood" and "A bad word", published in the journal Estudios in April and May 1918 respectively. Analysis includes its protagonists and the contextual framework that it housed them in the perspective of what the critic Jorge Panesi called "hidden controversy".

Keywords: Ricardo Rojas, Juan de la Cruz Puig, controversy

Recibido: 30/01/2019

Aceptado: 15/01/2021

120020150100117 Ubacyt Mod. I. “Textos fundacionales, narrativas funcionales: Chile y Río de la Plata”, Facultad de Filosofía y Letras, Universidad de Buenos Aires, 2016-2020. 
En 1917 Ricardo Rojas (1882-1957) publicaba el primero de los cuatro tomos que constituirían su Historia de la Literatura Argentina. Rojas fue creador y primer docente de la cátedra de Literatura Argentina en la Facultad de Filosofía y Letras de la Universidad de Buenos Aires, fundador y director del Instituto de Literatura Argentina, decano de la misma Facultad y rector de la Universidad de Buenos Aires. Docente, historiador, editor, crítico, folclorista, dramaturgo, autor prolífico de ensayos, narrativa y poemas, Rojas —ejemplo acabado del homo academicus bourdieusiano-, desde la escritura y la gestión educativa, se propuso moldear el relato de la memoria nacional y estimular el nacimiento de una generación de intelectuales capaces de compartir y reproducir ese relato y el ideario que lo sustentaba. Indudablemente, la Historia de la literatura argentina, cuyo título completo es Ensayo filosófico sobre la evolución de la cultura en el Plata, fue pieza fundamental de ese proyecto. El contexto socio-cultural que dio cabida a esta, una de los primeras historias de la literatura en América Latina, ha sido sobradamente estudiado por la crítica, de manera que sintetizaré diciendo que a fines del siglo XIX tuvo comienzo el período en el cual la literatura de la región, más allá de la función estética, fue constituyéndose como un discurso performativo de la nación, ${ }^{2}$ discurso que se consolidó a comienzos del siglo siguiente con "[1]as conmemoraciones de los Centenarios de las revoluciones de independencia, que adquirieron una dimensión simbólica especial pues se convirtieron en un hito fundamental del largo y complejo proceso de 'invención de las naciones"” (Suriano 19).

En ese sentido, ya en 1908 Rojas postulaba —desde el prólogo de un conjunto de ensayos publicados en París con el título de Cosmópolis- que el acceso al pasado nacional era posible únicamente a partir de una visión conjunta política y estética, al aseverar que "el pasado de una nación” no debía buscarse solamente en "la gesta heroica de sus orígenes," sino en "la remota leyenda donde se renueva el arte” (1908: VIII). Mientras que, en el prólogo de su Historia, unos años después, subsumía en un mismo gesto la historización de la literatura del país y la definición del "ser nacional" (34), creando un canon que, en la sistematización del archivo, desbrozaba la masa de textos para que en ella pudiera leerse - inequívocamenteel relato de la nación. De esta manera, explica Laura Estrin, Rojas “ordenó la literatura argentina como materia nacional en un sistema estético de ciclos", fundiendo lo filológico, lo didáctico y lo político en un plan que prescribía qué enseñar, cómo

2 Ya en 1844, por ejemplo, José Manuel Valdez y Palacios publicaba un Bosquejo sobre el estado político, moral y literario del Perú en sus tres grandes épocas y en 1883, Pedro Pablo Figueroa, convocado por Francisco Lagomaggiore a realizar un "bosquejo histórico" de la literatura nacional de Chile, refería que el heroico pueblo mapuche, tras el bautismo de la civilización, se tornó dócil y "efusivo en la unidad nacional" (1891: 12). 
enseñar, dónde y con qué fines "mostrar la literatura" (222). Así, Rojas inscribe su Historia en un sistema crítico de cuño propio que le permitirá entender la literatura, más allá de la coyuntura de sus elementos específicos, como manifestación estético-social "fundada en la evolución" de la "vida espiritual" del país (VI).

Excepto algunas voces disonantes como la del crítico Paul Groussac, ${ }^{3}$ la obra fue recibida con el beneplácito esperable para un autor que, pocos años más tarde, sería galardonado con el premio Nacional de Literatura y reconocido como figura de referencia por los jóvenes encuestados en la revista Nosotros, “ "órgano de consagración y difusión cultural” del momento (Sarlo 215). Además, en 1928, Rojas fue reconocido como magnífico "poeta", "prosador" y "maestro" por una Comisión de Homenaje que editó un volumen en el que se reseñaban sus veinticinco años de labor literaria (Chiáppori 8). ${ }^{5}$ Uno de los apartados de ese volumen refería los juicios laudatorios que había concitado la Historia de la literatura en boca de figuras de consolidada reputación en la época, entre las que se contaban Leopoldo Lugones y Alfonsina Storni. ${ }^{6}$

Existe, sin embargo, un extenso artículo publicado en abril de 1918 en la revista Estudios donde la Historia de la literatura argentina es considerada un sinsentido que debe ser denunciado, una ofensa que pone en riesgo la integridad de la literatura castellana, e incluso de la nación. Su autor es Juan de la Cruz Puig y el artículo lleva el título de "Una afrenta y una falsedad". Al mes siguiente, Ricardo Rojas ejerció su derecho a réplica a través de otro artículo en la misma revista: "Una mala palabra". ${ }^{7}$ Este trabajo propone el análisis de ese debate, breve y desconocido por la

3 El escritor y erudito Paul Groussac (1848-1929) nació en Francia pero vivió en Argentina desde los dieciocho años de edad. En 1885 se convirtió en director de la Biblioteca Nacional y en ese cargo permaneció hasta el año de su muerte.

4 La revista Nosotros, fundada en Buenos Aires por Alfredo Bianchi y Roberto Giusti, desarrolló sus actividades entre 1907 y 1920, y ocupó un lugar especialmente destacado en el ámbito cultural argentino de la primera mitad del siglo XX.

5 "Más allá de gustos o disgustos", dice Patricio Fontana, "más allá de coincidencias o disidencias, nadie podría negar — nadie debería negar — la importancia y, sobre todo, la ambición del trabajo de Ricardo Rojas al encarar, y llevar a buen término, su Historia de la literatura argentina" (2). Diana Sorensen, incluso, considera que Rojas es el creador de la literatura argentina como disciplina dado que, a través de su obra, generó el paradigma de la historia literaria del país (203).

6 La publicación de la Historia es evidentemente, como señala Altamirano (201), un gesto político fundacional de la literatura argentina en el circuito académico, y así lo ha perpetuado la crítica. Sin embargo, Gustavo Bombini demuestra que, en el ámbito de la educación media, desde fines del siglo XIX existieron intentos embrionarios en textos de preceptiva literaria como el de García Velloso en 1896, aunque no tuvieron el alcance del de Rojas (91-97).

7 Agradezco muy especialmente la valiosa colaboración, para acceder a materiales inéditos, de la pro- 
crítica especializada, deteniéndose, en primer lugar, en sus protagonistas y el marco contextual que los albergó, para luego considerar a ambos en la perspectiva de lo que el estudioso Jorge Panesi denomina "polémicas ocultas", entendiendo que existen polémicas constitutivas de una cultura o parte de ella, que perduran a través del tiempo, y si bien parecen superadas, esta superación es sólo aparente porque vuelven, revitalizando "nuevas formas de discusión, cancelando otras y reabriendo viejas discusiones” (Panesi 1).

\section{I.}

"A lo largo la primera década del siglo XX, camino al Centenario" dice Carola Hermida, "se publica [en Argentina] una importante serie de antologías, consideradas como dispositivos particularmente valiosos en el marco de las operaciones montadas para este aniversario. . .". Así, aparecen por ejemplo, los “parnasos”, en los que se alojan precisamente "los mejores escritores argentinos" que demuestran la existencia de una literatura y una lengua nacionales: "el Parnaso argentino de Guillén de Cardona (1903), El Parnaso argentino de José León Pagano (1904) y los diez volúmenes de la Antología de poetas argentinos compilada por Juan de la Cruz Puig (1910)" (2). La compilación de Puig estaba formada por copiosos volúmenes, a lo largo de los cuales, explica Aníbal Salazar, "se levanta un esbozo arquitectónico de la historia poética argentina desde los tiempos de la Colonia hasta principios del siglo XX" (177). Si bien la región rioplatense presenta, continúa Salazar, "uno de los panoramas de mayor fecundidad en lo que a la tradición antológica se refiere (sólo son comparables en el ámbito hispánico los casos de España, México y Cuba)", recién en 1926, la publicación de La Antología de la poesía argentina moderna de Julio Noé aporta una mirada crítica sobre la génesis y evolución de la creación poética del país". Sin embargo, "la Antología de poetas argentinos de Juan de la Cruz Puig es un precedente no desdeñable al respecto", dado que su primer paso consistió "en la reunión de todo el material existente que posteriormente habría de ser organiza-

fesora Soledad Zapiola, integrante del Área Archivo Documental e Investigaciones del Museo Casa de Ricardo Rojas.

8 Los tomos que componen la Antología se titulan: 1. La colonia, 2. La Revolución, 3. Paz y libertad, 4. Patria y honor, 5. La sociedad de mayo, 6. El clamor de los bardos, 7. Nueva alborada, 8. Laúdes y guitarras, 9. Lira argentina, y 10. Auroras y ocasos. La obra fue dedicada a su esposa, Rosa Lejarza: consigno este dato, en apariencia irrelevante, pues, nos permite ponderar una faceta adicional de este texto de Puig ligada a lo doméstico, en tanto, como indica Florencia Calvo citando a Derrida, la dedicatoria es un elemento paratextual mediante el cual el autor busca inscribir su texto dentro de una dimensión autobiográfica (48). Respalda esta idea el hecho de que, en el "Proemio" del primer tomo, Puig indica que este "[n]o es trabajo profesional de gabinete, sino eutrapelia ("broma amable') del hogar" (Antología V). 
do e interpretado por críticos y especialistas" (178). "El vasto proyecto de Puig", concluye Salazar, "está cargado de buenas intenciones, aunque no logra madurar el proceso vivo de la poesía nacional; más bien habría que considerar dicha obra como una protohistoria, los cimientos primitivos para un futuro ensayo" (180). Ahora bien, si como dice Carlos Battilana, "las antologías son mapas literarios que no dejan de incluir un canon" (1), un análisis somero de La colonia, primer tomo de la Antología editada por Puig, nos permitirá indagar cuál es el mapa literario que traza y de qué manera constituye ese canon.

La colonia lleva dos epígrafes significativos: "La Patria es una nueva musa que influye divinamente" de fray Cayetano Rodríguez" y "Nuestros poetas han sido los sacerdotes de la creencia de mayo" de Juan María Gutiérrez. Se hace evidente que Puig liga el nacimiento de la literatura nacional al momento de la independencia y que, en ese marco que conjuga sin fisuras perceptibles lo político y lo estético, sacraliza la voz del poeta como numen privilegiado de un momento fundacional. $\mathrm{Si}$, además, echamos un vistazo sobre la actuación político-cultural de los autores elegidos para los epígrafes, veremos que esta anticipa, sin dudas, la perspectiva urbana y letrada que guiará la composición de la Antología en su conjunto. El franciscano Cayetano Rodríguez, congresista en Tucumán durante la declaración de la Independencia, fue convocado, además, por su condición de poeta, a escribir el texto del futuro Himno Nacional Argentino. Rodríguez cumple el encargo en 1812 pero el texto no despierta en el auditorio la emoción esperada y un nuevo encargo de la Asamblea General Constituyente convierte a Vicente López y Planes, un año después, en el creador de la canción patria. Sin embargo, en 1824 Ramón Díaz incluyó a Rodríguez en La Lira Argentina, donde se recopilaron todas las piezas poéticas o de simple versificación que habían salido en Buenos Aires durante la guerra de independencia (Casiva 325). Por otra parte, Juan María Gutiérrez, autor del segundo epígrafe citado por Puig, es quien publica, en 1860, una biografía de Cayetano Rodríguez, al que reserva un lugar destacado dentro de escritores, oradores y hombres de estado del país. Gutiérrez, por cierto, fue amigo personal de Esteban Echeverría — figura fundante de la literatura rioplatense- y participó en el Salón Literario y la Asociación de Mayo, cuyos integrantes, nucleados en un

9 "La literatura de la independencia", dice Pedro Luis Barcia, "es unánime en las motivaciones de sus cantos y uniforme en la encarnación verbal de aquellas. Toda esta poesía arranca, básicamente, de una misma actitud de entonada celebración del 'Mes de la Patria' o 'Mes de América' . . . Este motivo se mantendrá con vigor suscitador de poesía a lo largo de los años. El sol de Mayo y la aurora precursora de su surgimiento serán elementos reiterados en cada reverdecimiento poético anual. 'La Patria es una nueva musa que influye divinamente’, decía fray Cayetano Rodríguez ... A partir de este motivo, cuanto hecho militar o civil reafirme el camino de la independencia iniciado en Mayo, encontrará su celebración poética" (LXVI). 
primer momento en torno a las ideas que el movimiento romántico propagaba desde Europa, pronto sucumbieron a las presiones del entorno y asumieron una postura netamente política frente al gobierno de Juan Manuel de Rosas: ${ }^{10 ~ “[d] e l ~}$ salón, como propuesta de lugar de pertenencia intelectual, al partido como lugar de pertenencia política" (Iglesia 359).

Así, las poesías que se recogen en esta obra, como explica el mismo Puig en el "Proemio" de este primer volumen de su Antología, son hojas al viento que se han dejado perder en el camino "a través de la epopeya de la emancipación, la tragedia de la anarquía y la lírica de nuestro federalismo constitucional" (V). En este prólogo, además, considera que la mejor introducción para su obra sería el decreto de 1822 con que Bernardino Rivadavia — primer presidente de las Provincias Unidas del Río de la Plata_ ordenó editar todas las poesías que se habían escrito desde 1819 hasta ese momento y solventar la publicación con el saldo del fondo de guerra de la independencia (VII). Más aún, Puig establece una genealogía de obras antológicas de la que se considera partícipe, en tanto depositario de una tradición que comienza con La lira argentina y la Colección de poesías patrióticas en 1824 y 1827, respectivamente, y finaliza en 1895 con la Antología de poetas hispano-americanos de Marcelino Menéndez y Pelayo. El "Proemio" concluye citando nuevamente el epígrafe de Rodríguez, al que se vincula expresamente con "el objeto" de la compilación, mientras justifica la ordenación cronológica elegida como condición necesaria para deleitarse con "el dulce son de las vihuelas coloniales, el fragor de los combates de la revolución de mayo, las dianas de las victorias de los ejércitos patriotas, el himno de la libertad, el canto de la paz, el estrépito del progreso y el rumor de las crecientes multitudes de sus ciudades (XV)". Acorde con esto, las poesías compiladas en el volumen finalizan con la transcripción de un extenso poema en octavas reales: "La reconquista de Buenos Aires por las armas de S.M. Católica el 12 de agosto de 1806", en el cual Manuel Pardo de Andrade canta a la ciudad recuperada y a aquellos que entregaron su sangre para que esto fuera posible (307-308).

El mapa que traza Puig desde el tomo inaugural de su Antología es inequívoco: centrado en el núcleo urbano más importante del país, privilegia un relato épico de la reconquista de la ciudad de Buenos Aires tras las invasiones inglesas ocurridas en 1806 y 1807, años previos a la independencia de la que fueron antecedente inmediato. De la misma manera, el canon que se establece a partir de este mapa da cabida únicamente a nueve letrados, criollos o españoles, cuya labor de militares,

10 Para algunas de las múltiples implicancias del enfrentamiento entre unitarios y federales, cristalizado en las figuras de Esteban Echeverría y Juan Manuel de Rosas en torno a un texto fundacional de la literatura rioplatense como El Matadero, véase el lúcido trabajo de Jitrik (1971). 
canónicos o jurisconsultos alternaron con su dedicación a las letras, mientras que, pese a que el volumen se titula La colonia, no existe ni una mínima referencia, ya no a las culturas que precedieron a la llegada de los españoles, sino a poemas escritos en los siglos XVI y XVII, como el Romance (ca. 1540) de Luis de Miranda o el Libro de varios tratados (ca. 1660) de Luis de Tejeda.

\section{II.}

En 1924, Paul Groussac recopila una serie de conferencias y artículos de años anteriores y los publica con el título de Crítica Literaria. En el "Prefacio" a esta edición, Groussac anuncia un segundo tomo en el que se ocupará "de personas y cosas del país” y, a continuación, emite, sin nombrarla, un juicio lapidario sobre la Historia de Rojas:

Por cierto que usaré allí del primer derecho de la crítica, que consiste en hacer caso omiso de las obras inferiores al mediano nivel . . . Es así como, verbigracia, después de oídos con resignación, dos o tres fragmentos en prosa gerundiana de cierto mamotreto públicamente aplaudido por los que apenas lo han abierto, me considero autorizado para no seguir adelante, atendiéndome, por ahora a los sumarios o índices de aquella copiosa historia de lo que, orgánicamente nunca existió. Me refiero especialmente a la primera y más indigesta parte de la mole ... balbuceos de indígenas o mestizos, remedos deformes de crónicas o poemas peninsulares, nociones bobas de etnografía y folk-lore, etc., que tanto tienen que ver con la obra literaria como nuestro "rancho" pajizo con la arquitectónica (VIII).

Las objeciones de Groussac, así como su carencia argumentativa, fueron advertidas por Borges, quien las incluyó en el ensayo "El arte de injuriar" como ejemplo poco ilustre del género: ${ }^{12}$ sin embargo, esta inclusión parece haberle dado una trascendencia inmerecida a aquello que fue poco más que un exabrupto. Pese a esto y aunque no desarrolla ni sostiene con argumentos su crítica a la obra de Rojas, Groussac esboza tres objeciones constitutivas de aquello a lo ya aludí como "polémicas ocultas" y que serán, por lo tanto, materia de debate en los años poste-

11 "El arte de injuriar" fue escrito en Adrogué en 1933, tal como se indica al final del ensayo, pero se publicó en 1936 integrando la compilación Historia de la Eternidad.

12 "No comete pecados en la sintaxis, que es eficaz, pero sí en el argumento que indica. Reprobar un libro por el tamaño, insinuar que quién va a animársele a ese ladrillo y acabar profesando indiferencia por las zonceras de unos chinos y unos mulatos, parece una respuesta de compadrito, no de Groussac" (Borges 53). 
riores: la existencia orgánica de un todo al que pueda reconocerse como "literatura (nacional) argentina", la pertenencia "legítima" a ese todo de algunos integrantes como indios y mestizos, y la dependencia de la literatura argentina con respecto a los modelos centrales. De alguna manera, Juan de la Cruz Puig anticipa estos mismos argumentos en "Una afrenta y una falsedad", sin duda la crítica más extensa y pormenorizada que se haya publicado en época contemporánea a la aparición de la Historia de la literatura argentina.

\section{III.}

Puig da comienzo a su artículo indicando que:

Los estudios literarios son ahora una de las cosas más caprichosas que existan porque bajo esa etiqueta se puede ya hablar de todo lo que se quiera, y escribir sobre todo y sobre nada. Las desinteligencias comienzan ahora desde el concepto de lo que es Literatura ${ }^{13}$ (Estudios 262).

Y unas pocas líneas más abajo, después de esta introducción general, expresa sintética y claramente el motivo puntual de su artículo:

El disparate que denuncio y el hecho que considero afrentoso para nuestra literatura castellana es el que se traigan las lenguas aborígenes a formar parte integrante de ella, el de que se junten bajo el alero plebeyo . . . a la barbarie que no sabe ni lo que son letras, con la civilización que ha hecho de ellas un culto, y estima como al mejor exponente de sus virtudes ... Esto es una afrenta que se hace a nuestra cultura (Estudios 262).

Desde el inicio, entonces, Puig se lanza al ruedo a disputarle a Rojas la paternidad de la literatura nacional, — que se perfilaba como objeto impreciso aún pero no por ello menos codiciado-, y por ende, el derecho de decidir quiénes podían ser legítimamente incluidos en dicho corpus. ${ }^{14}$ Por cierto, desde el inicio también,

13 "Pudo variar el criterio con que se entendiese lo que era Literatura", dice Puig más adelante, "hasta el extremo de que el general Mitre sostuviera públicamente, cuando se trató de establecer esa enseñanza de la literatura nacional en los colegios nacionales, que todavía no teníamos material suficiente como para justificar el hecho" (Estudios 263).

14 Para Patricia Funes: "las fundamentaciones sobre la existencia o la voluntaria construcción de una "historia de la literatura nacional" descubre en sus mecanismos de selección, hermenéutica y fundamentación el conflicto por definir los significados de la identidad nacional. Constructivistas o identitarias, 
los lineamientos de la argumentación, desarrollada a lo largo de todo el artículo, muestran la presencia de la antinomia de neta raigambre colonial, "civilización y barbarie", que Puig se afana por resaltar a través de las cursivas que destacan lenguas aborigenes frente a letras, en la cita anterior. Así, la polémica entablada visibiliza una fractura "más oculta y más vasta": civilización y barbarie, dice Jorge Panesi, "es a la vez un principio dicotómico de esclarecimiento histórico, sociológico y cultural, una intervención polémica en el plano de las ideas que abre ... una brecha de largo alcance reinterpretada y vuelta a interpretar en los contextos de crisis política" (12). Denominación cristalizada de un colectivo heterogéneo y dinámico, civilización y barbarie remite también a "la cuestión del europeísmo y el localismo, la vindicación de las raíces hispánicas, la pureza del idioma nacional . . . del casticismo jerárquico y esencial", que se tradujo en "lingüístico afán defensivo y belicoso" (2). No es casual, entonces, que en este marco, la polémica en torno al texto de Rojas esté focalizada en "la cuestión del verbo".

Puig hace consistir la "afrenta" infringida por la Historia de la literatura argentina en la síntesis — a su juicio- imposible que equipara dentro de los cánones de la literatura nacional, "el verbo de Cervantes con el verbo de Calfucurá", transmutada, además, en indecible "vergüenza" al provenir de un profesor cuya cátedra pertenece a la universidad nacional. Y "para que la afrenta sea más completa y duradera", concluye, "nos brinda este presente con todos los honores de un volumen de más de quinientas páginas" (Puig 263), inaugurando el tópico deprecativo sobre la extensión de la obra de Rojas del cual, pese a sus ironías sobre Groussac, también entre otros- participó Borges, tal como reseña Mesa Gancedo en "Ricardo Rojas y la desproporcionada Historia de una literatura nacional" (304).

Puig acusa recibo del peligro de la falta de límites que entraña la concepción de literatura propuesta por Rojas, "que puede considerar como literario a todo el LOGOS ABORIGEN, y presentar las jergas guaicurúes, quichuas, tobas, guaraníes ... al lado de todos los escritos castellanos" (264), pues esto lleva a la disolución de la diferencia entre el mundo letrado y el mundo salvaje: "iLos conceptos de civilización y barbarie no son allí antitéticos. .. !" (264). "Atonía ética", para Puig, que simplemente encubre la acción redentora de una cultura superior que incorpora a su idioma algunas voces de "los salvajes redimidos" (265), y puede condensarse en la frase palmaria de "[l]a República Argentina no incorporó el desierto a la civilización con la coyunda del matrimonio. . . sino con la tercerola y el remington" (266).

particularistas o universalistas, tradicionalistas o vanguardistas, la cuestión excede el campo literario y es bien demostrativa de vocaciones más pretensiosas" (100). 
Ahora bien, la argumentación con la que Puig intentará socavar la estructura que sustenta el primer tomo de la Historia de Rojas consiste en demostrar que la poesía gauchesca no reviste carácter popular, habida cuenta de que se parte del error de considerar que "el logos indígena" puede formar parte de la literatura argentina (267). Así, "Una afrenta y una falsedad" acumula ejemplos que muestran que el vocablo "gaucho" remite en su origen a un referente culto, y estos ejemplos están dirigidos a demostrar que su "cuna no fue el galpón, ni el rancho, ni la pulpería, mucho menos la toldería, sino, las salas de redacción de los periódicos . . . de las imprentas de los expatriados en Montevideo" (378). De esta manera, nunca podría pensarse que el género gauchesco fue el resultado de "la evolución de un estilo inferior" (280). El corolario de Puig consiste en ironizar sobre la "horrorosa ingenuidad" de Rojas respecto de una expresión del emblemático poema de Juan Baltazar Maciel, "Canta un guaso en estilo campestre los triunfos del Excelentísimo Señor don Pedro de Cevallos”, considerado el primer antecedente del género gauchesco. El interés especial de Puig en relación con esta composición se justifica en tanto, como explica Schvartzman, el poema de Maciel, escrito en 1777, permaneció inédito durante más de 130 años, hasta que el mismo Puig lo descubrió entre los documentos de la colección Segurola y lo publicó en el primer tomo de su Antología (61-2). Rojas, dice Puig, lee en la expresión "he de puja, el caballero" del texto de Maciel — "He de puja, el caballero/y bien vaya toda su alma/que a los Portugueses jaques ${ }^{15}$ / ha zurrado la badana" - , ${ }^{16}$ el "hideputa cervantesco" y el "hijuepucha" de los payadores posteriores (281), verdadera abyección que borra el sentido encomiástico que el poema conlleva. Por el contrario, Puig asevera que la expresión remite a "y es de puja, el caballero", considerando que el vocablo "puja" significa "exceso o ventaja” (281). Además, Rojas pasa por alto, dice Puig, que el enunciador del poema no es un "guaso criollo" sino un "guaso portugués" (282) y cita como prueba la presencia en el poema del vocablo "germana", supuestamente de origen lusitano. Vinculado con lo anterior, el artículo finaliza con la ironía de una pregunta retórica dirigida ahora, no al autor del artículo agraviante, sino a la institución pública que lo alberga: “¿Qué dirá la Facultad de Letras de Buenos Aires de esta estupenda interpretación cervantesca del profesor de Historia de la Literatura Argentina?” (281).

15 Jaque: "Valentón, perdonavidas" (Diccionario de la Real Academia).

16 Zurrar la badana (a alguien): "Maltratarlo físicamente o de palabra" (Diccionario de la Real Academia). 
Más allá de la pertinencia de los reparos esbozados por Puig, ${ }^{17}$ lo que me interesa poner de manifiesto es que este último reclamo específico —otra arista de las "polémicas ocultas" - va mucho más allá del género gauchesco, y se inscribe, fundamentalmente, en la coyuntura crítica que se produce a fines del siglo XIX con la llegada al país de la primera ola inmigratoria, cuyo mayor auge tiene lugar en la década del 20, y con las disputas en torno al idioma y a la lengua literaria, tal como explica Mariano Olivetto (1). Frente a estas, el sistema escolar en Argentina "procuró construir una norma estético-lingüística escolar que cumpliera una función modeladora frente a las prácticas lingüísticas foráneas, mientras que el Estado, en tanto ente educador, "reconocía a los intelectuales como portadores de una verdad cultural de la nación” (2-3).

\section{IV.}

"Una mala palabra", el artículo donde Rojas responde los cuestionamientos esgrimidos por Puig, es breve y contundente. En menos de la mitad de las páginas utilizadas por este, Rojas delimita el que va constituirse como objeto de su argumentación y a él se dirige:

Todo se reduce a afirmar: $1^{\circ}$ Que yo proclamo un retorno a la barbarie indígena, al estudiar el folklore americano; $2^{\circ}$ Que considero al gaucho como una raza, cuando fue solamente un tipo social; $3^{\circ}$ que he interpretado equivocadamente una palabra de cierto romance gauchesco (Estudios 329).

Con respecto a la primera afirmación, Rojas contesta que, por el contrario, él aboga por la cultura universal y remite a las conclusiones de Los gauchescos que lo corroboran, y a los artículos laudatorios aparecidos en publicaciones académicas de la época como el Boletín de la Federación Universitaria y la revista Ideas, del Ateneo de Estudiantes Universitarios (330). Así, además, insinúa lo que más adelante va a afirmar: Puig no forma parte del público especializado que ha leído su obra. Con respecto al segundo cuestionamiento, Rojas remite a una página de su libro, donde indica que "el gaucho no es el tipo específico de una raza aborigen", sin dejar de sugerir que Puig no ha leído Los gauchescos, al menos de manera completa (330). La tercera cuestión, que involucra la interpretación de un vocablo, —la "mala palabra" del título—, "no puede ser más insignificante en la totalidad de la obra", dice Rojas, "pero mi desesperado fiscal hace de ello el argumento Aquiles de su pro-

17 De hecho, estudios posteriores demostraron que Puig estaba en lo cierto con respecto al origen culto del género. Véase, al respecto, el interesante trabajo de Moure (2010) donde afirma que "[1]a "lengua gauchesca" nació escrita" (44). 
ceso. Entonces, clavémosle el último dardo en ese talón” (331). Rojas refuta este argumento tanto desde el punto de vista lógico como desde el filológico: no puede pensarse que el autor del romance sea portugués, como propone Puig, puesto que celebraría en su poema el vencimiento de sus propios compatriotas, mientras que el vocablo germana, que Puig aduce de origen lusitano, dice Rojas, es en realidad la forma arcaica del castizo hermana (332). Pero, además, Rojas cita una serie de especialistas en filología de la época que explican que la voz hideputa es una expresión elogiosa, y así se registra en Cervantes: “[e]sta exclamación”, dice Rodríguez Marín en una edición anotada de Cervantes, "muy mal sonante hoy, se prodigaba mucho antaño, y a menudo, como en el caso presente, . . . en señal de admiración y como el más acabado elogio" (333). "Para cosa tan nimia y victoria tan fácil", concluye Rojas, "podría, ciertamente, haberme evitado el trabajo de escribir estas líneas" (334), sin embargo, tan ímproba tarea se justifica —más allá del adversario, que no pertenece al círculo de la "crítica ilustrada" (334) — porque la revista estaba destinada a los estudiantes de los colegios católicos del país. Y es allí hacia donde conduce el debate que le interesa sostener.

Rojas elige interlocutores que considera de su talla: "los padres ilustrados del Salvador" y la "Academia Literaria del Plata"18 (334), editores de la revista. A ellos manifiesta su asombro porque un artículo aparecido en una publicación vinculada a la Orden de los jesuitas, como Estudios, cuestiona la presencia de las razas indígenas en la cultura de la región. Quienes iniciaron el estudio de los pueblos originarios, recuerda Rojas, fueron los primeros evangelizadores ignacianos, de manera que él está continuando aquello "que los padres de la Compañía en otro tiempo" comenzaron (335). Efectivamente, en 1585 se trasladaron los primeros jesuitas al Río de la Plata por orden del obispo del Tucumán, Francisco de Vitoria, y con ellos comenzó la implementación de los instrumentos destinados a la evangelización que la orden privilegiaba, uno de estos fue el estudio de las lenguas indígenas, que dio como resultado los primeros vocabularios y gramáticas sobre las lenguas originarias de la región. Rojas, para quien la historia de la lengua era inseparable de la historia de la literatura y la historia cultural (Estrin 225), fue el primero en incluir dentro de la historia literaria del país el accionar de los misioneros de la Orden, a los que denominó "evangelizadores filólogos" (1917: 80) y "filólogos coloniales"

18 En la página oficial de la Academia puede leerse: "[l]a Academia del Plata fue fundada el 20 de abril de 1879 a iniciativa de alumnos del Colegio del Salvador que poco antes de egresar propusieron al Rector la fundación de un centro literario, a fin de 'fomentar su amor a la filosofía católica y a la literatura, y conservar el espíritu cristiano recibido en esa institución'. En el Estatuto de la asociación se establece que su objetivo es 'promover todas las manifestaciones de las ciencias, las letras y las artes que den testimonio del pensamiento católico de la vida cultural argentina"'. 
(109). ${ }^{19}$ Significativamente, unos años después el jesuita Guillermo Furlong Cardiff, integrante de la Academia Literaria del Plata y asiduo colaborador de la revista Estudios, retoma esta idea en el capítulo "Lingüistas y filólogos" de su muy conocido Los jesuitas y la cultura rioplatense (35). ${ }^{20}$ Por otra parte, en 1937 el mismo padre Furlong cita expresamente a Rojas como referente en su discurso de ingreso a la Academia Nacional de la Historia (Imolesi 17).

Rojas no solamente se refiere a la actividad de los jesuitas en los capítulos "La raza nativa", "La lengua nativa" y "La tradición de los indios" del primer tomo de su Historia, también dedica exclusivamente a ellos los capítulos "La escuela teocrática de Córdoba" y "La expulsión de la Compañía de Jesús" del segundo tomo de su obra, inédito en ese momento, y así lo anuncia en "Una mala palabra":

En el segundo tomo de mi Historia, que se titula Los coloniales, estudio las crónicas de la conquista y la obra intelectual de las órdenes religiosas, como podrá verlo el señor director por el Índice que le envío (Estudios 335).

Estos capítulos constituyen el estudio más extenso y pormenorizado de principios del siglo XX, inserto en una historia de la literatura, ${ }^{21}$ sobre la instalación y desarrollo de la Orden en el Río de la Plata, pero además, son un reconocimiento elogioso de la labor de los jesuitas a largo de toda la historia del país. "[L]a Compañía de Jesús destácase," dice Rojas, "por la complejidad y trascendencia de su obra, durante los dos siglos en que afrontó la educación moral e intelectual de la sociedad argentina" y porque — posteriormente-, "[a] través de sus historiadores ... continuó influyendo ... después de su expulsión (1767) y después de nuestra emancipación (1810)" (Los coloniales 334-336).

Desplazado el objeto de la controversia del enunciado al enunciador, las objeciones de Puig se invalidan no por su contenido sino porque quien enuncia no pertenece al círculo de interlocutores calificados reconocido por Rojas, y así parece quedar resuelta la cuestión. Sin embargo, en los últimos tramos de su artículo Rojas

19 Recordemos que, en 1922 junto al Instituto de Literatura Argentina, Rojas creó el Instituto de Filología y Literaturas Hispánicas en la Facultad de Filosofía y Letras de la Universidad de Buenos Aires.

20 Más aún, Guillermo Furlong concluye este capítulo de su libro haciendo alusión al padre Lorenzo Hervás, quien realizó por primera vez una clasificación de las lenguas americanas, gracias a lo cual "surgió a fines del siglo XVIII la ciencia filológica" (42).

21 Incluso, Rojas compite con la historiografía de la época, así lo indica Rómulo Carbia en su Historia de la historiografía argentina (XX-XXI), obra en la que menciona reiteradamente la Historia de Rojas. Por otro lado, Carbia pertenecía a la Academia Literaria del Plata desde 1906. 
va a confrontar a Puig en el único terreno que justifica la contienda a nivel individual, el de la ética pública:

El personaje de quien tratamos, que es ingeniero de profesión, "fabricó" hace tiempo una Antología en diez tomos, donde publicó por suyo casi todo el material de la Colección Gutiérrez, que se guarda en la Biblioteca del Congreso, y el de la Colección Segurola, que se guarda en la Biblioteca Nacional. El "antologista" era subsecretario del Ministerio de Hacienda —-función ajena a las letras-, cuando obtuvo para su edición varios miles de pesos en los pingües días del Centenario (Estudios 335-336).

Es bien conocida la importancia que Rojas atribuía, dentro de su proyecto académico-institucional, a la recopilación y organización de materiales en archivos documentales, no para uso personal sino como fuente y sustento del relato nacional. Así, después de convertirse en 1913 en el primer docente de la cátedra de Literatura Argentina, fundó el Instituto correspondiente cuyo fondo inicial consistió en dos donaciones documentales: ${ }^{22}$ una de las cuales fueron los documentos pertenecientes a Juan María Gutiérrez, justamente aquellos de los que Puig se habría servido como propios. Es bien sabido también, el cuidado que tenía Rojas en el manejo de los fondos públicos, él mismo aseguraba orgullosamente que los ejemplares que conformaron la biblioteca de dicho Instituto se consiguieron mediante donaciones o adquisiciones, obtenidas a precio ínfimo. Además, en esta misma época, editó la Biblioteca Argentina, cuyos volúmenes, dirigidos a obreros y estudiantes, indicaban en la contratapa que dicha publicación salía "a la luz sin subvención del Estado, librado su éxito al apoyo del pueblo" (“Apéndice” 650).

Los párrafos finales del artículo dan cuenta nuevamente de una notable habilidad discursiva que le permite a Rojas un último desplazamiento del foco de discusión, que se centra, ahora, en la Antología poética de Puig. Dado que la argumentación ha evidenciado que Puig no tiene ni la erudición ni la altura ética necesaria para emitir un juicio sobre producción académica alguna, Rojas concluye, anudando en una frase ambas cuestiones: "Si alguna vez aludí a esa Antología, es porque se trataba de una mala edición a expensas del erario público" (Estudios 337).

22 En el artículo $1^{\circ}$ de la Ordenanza de Creación del Instituto de Literatura Argentina se especificaba que este estaba destinado "a la conservación de los documentos bibliográficos, iconográficos y manuscritos que puedan interesar a la historia de nuestra literatura nacional" (4). 


\section{Casi una conclusión}

Al inicio de este trabajo propuse leer "Una afrenta y una falsedad" y "Una mala palabra", publicados en la revista Estudios en abril y mayo de 1918 respectivamente, en la perspectiva crítica de lo que Jorge Panesi denomina "polémicas ocultas". Y en ese sentido, creo haber podido evidenciar que los artículos de Juan de la Cruz Puig y Ricardo Rojas constituyen la primera polémica en torno a la Historia de la literatura argentina que, aunque breve y desconocida hasta el momento, no es menos significativa como punta visible de vastas "fracturas culturales constitutivas" que no se perciben en la superficie, "pero que estarían como un telón de fondo siempre renovado de las discusiones" a través del tiempo (Panesi1-4). De la misma manera, la dicotomía sintetizada como civilización y barbarie, puede ser entendida en tanto punta de iceberg de una profunda fractura cultural constitutiva no sólo de Argentina, sino de toda América Latina, que —innegablemente — apunta también a la cuestión de definir los límites y significados de la identidad nacional (Funes 100).

Para finalizar, casi diez años antes de la aparición del primer tomo de la Historia de la literatura argentina, Rojas había actualizado en Blasón de Plata la pregunta acuciante formulada por Sarmiento en 1883 sobre la condición de la "americanidad": “- ¿Somos europeos? — ¡Tantas caras cobrizas nos desmienten! ¿Somos indígenas?-”, y le había dado respuesta al incluir como destinatarios específicos del texto a "nuestros hermanos americanos" (Schiffino 4). "[F]uerte gesto simbólico", dice Carola Hermida, "que rompe con cierta tradición selectiva que busca cortar raíces con los pueblos originarios americanos para enlazar nuestro pasado con el europeo", así como lo hace Lugones posteriormente en Elpayador (2013: 224). Rojas va más allá, sin embargo. En Los gauchescos el gesto se vuelve materia y argamasa de la nación: la sangre indígena, sumergida e invisible, se concibe ahora como el río subterráneo que impregna las venas de lo genuinamente nacional (70), mientras que el relato de los orígenes se retrotrae — necesariamente- a un pasado que excluye lo europeo. "Datar nuestra génesis literaria en 1810", va a decir poco después en el segundo tomo de la Historia, Los coloniales, "fuera enfrentarnos con un fenómeno ya realizado, sin conocer los antecedentes que lo explican" (87). Ese relato — verdadero eje del debate — es el que Puig se siente en la necesidad de denunciar, por los riesgos que implica, como falso y afrentoso. Riesgos que se acrecientan para Puig, además, al ser enunciado desde una universidad pública en un momento en que las historias de la literatura — como dice Patricia Funes siguiendo a Hobsbawm (100) - adquirían verdadero protagonismo en el proceso de consolidación de los estados nacionales a través de una compleja ingeniería social que trabajaba, fundamentalmente, en el plano de las subjetividades y los materiales simbólicos. 


\section{Obras citadas}

Altamirano, Carlos. "La fundación de la literatura argentina". Altamirano, Carlos y Sarlo, Beatriz. Ensayos argentinos. De Sarmiento a la vanguardia. Buenos Aires: Espasa-Calpe, [1983] 1997: 201-209.

Barcia, Pedro Luis. La Lira Argentina o Colección de las piezas poéticas, dadas a luz en Buenos Aires durante la guerra de su Independencia. Edición crítica, estudios y notas. Buenos Aires: Academia Argentina de Letras, 1982.

Battilana, Carlos. (2010) "Un mapa de la poesía argentina. Reseña 200 años de poesía argentina". Bazar Americano. Web 03 Dic. 2018. < http://www.bazaramericano. com/pdf.php?.cod $=105 \ldots$.resenas.... resena $>$

Bombini, Gustavo. Los arrabales de la literatura. La historia de la enseñanza literaria en la escuela secundaria argentina (1860-1960). Buenos Aires: Miño y Dávila. 2004.

Borges, Jorge Luis. "El arte de injuriar". Historia de la Eternidad. Buenos Aires: Viau y Zona, 1936.

Calvo, Florencia. "La oreja y la pluma. La dedicatoria como huella de la autobiografía". Olivar 2001 2. 2 (2001): 41-63. Web 18 Nov. 2018. <http://www. olivar.fahce.unlp.edu.ar>

Carbia, Rómulo. Historia de la historiografía argentina (desde sus origenes en el siglo XVI). Edición definitiva. Buenos Aires: Coni, 1940.

Casiva, Fernando Matías. "Poéticas de fundación en La Lira Argentina". Revista Escuela de Historia 5.1. 5 (2006): 323-337.

Chiáppori, Atilio. La obra de Rojas. XXV años de labor literaria. 1903-1928. Buenos Aires: La Facultad, 1928.

Real Academia Española. Diccionario de la lengua española. Edición del Tricentenario. Actualización 2017. Web. 11 Nov. 2018 http://dle.rae.es.

Estrin, Laura. "La Historia de la literatura argentina". Actas de las I Jornadas de Historia de la Crítica en la Argentina. Buenos Aires, Facultad de Filosofía y Letras, (2009): 223-227. 
Figueroa, Pedro Pablo. Crónicas patrias. La Literatura Chilena, bosquejo bistórico, desde la colonia hasta nuestros días, escrito para la América Literaria como introducción de la sección chilena, obra que publica en Buenos Aires don Francisco Lagomaggiore. Santiago de Chile: El Correo, 1891.

Fontana, Patricio. "El crítico contra los "falsos discípulos": Ricardo Rojas lee a Sarmiento en la Historia de la literatura argentina”. Orbis Tertius XXI (2016): 1-13.

Funes, Patricia. "Leer versos con los ojos de la historia. Literatura y Nación en Ricardo Rojas y Jorge Luis Borges”. História 22. 2, (2003): 99-120.

Furlong, Guillermo. Los jesuitas y la cultura rioplatense. Montevideo: Urta y Curbelo, 1933.

Groussac, Paul. Crítica literaria. Buenos Aires: Jesús Méndez e hijo, 1924.

Gutiérrez, Juan María. "Fray Cayetano José Rodríguez". Apuntes Biográficos de Escritores, Oradores y hombres de Estado de la República Argentina. Buenos Aires: Imprenta de Mayo, 1860. VII.

Hermida, Carola. "Antologías literarias del Primer Centenario: laureles y trozos selectos". Actas del Cuarto Congreso Internacional CELEHIS de Literatura española, latinoamericana y argentina. Mar del Plata. 2011. Web. 4 Dic. 2018. <http://www. mdp.edu.ar/humanidades/letras/celehis/congreso/2011/actas/indtitulo.htm>

. “Tres introducciones”. Estudios de Teoría Literaria 2. 4 (2013): 223-234.

Iglesia, Cristina. "Echeverría: la patria literaria". Cristina Iglesia y Loreley El Jaber (dir.). Una patria literaria. Buenos Aires: EMECÉ, 2014, t. XII Historia Crítica de la Literatura Argentina.

Imolesi, María Elena. "De la utopía a la historia. La reinvención del pasado en los textos de Guillermo Furlong". Mélanges de l'École française de Rome-Italie et Méditerranée modernes et contemporaines. 2014: 1-37. Web. 16 Ag. 2018.<http:// journals.openedition.org/mefrim/1713>

Instituto de Literatura Argentina "Ricardo Rojas. Antecedentes y actividades". Buenos Aires, Universidad de Buenos Aires, Facultad de Filosofía y Letras, 1979.

Jitrik, Noé. "Forma y significación en El Matadero, de Esteban Echeverría", El fuego de la especie: ensayos sobre seis escritores argentinos. Buenos Aires: Siglo XXI, 1971: 63-98. 
Mesa Gancedo, Daniel. "Ricardo Rojas y la desproporcionada Historia de una literatura nacional”, Romero Tobar, Luis. Literatura y nación: la emergencia de las literaturas nacionales. Zaragoza: Prensas Universitarias de Zaragoza, 2008: 303326.

Moure, José Luis “La lengua gauchesca en sus orígenes”. Olivar 11.14 (2010): 33-47.

Olivetto, Mariano Javier, El problema de la lengua literaria: disputas y condiciones de transformación en la Argentina de 1920. Tesis de doctorado en Letras. Universidad Nacional de la Plata, 2014 Web. 6 Dic. 2018. < http:// www.memoria.fahce.unlp. edu.ar/tesis/te.1078/te.1078.pdf>

Puig, Juan de la Cruz Antología de poetas argentinos. Buenos Aires: Martín Biedma, 1910.

. “Una afrenta y una falsedad". Estudios. Academia Literaria del Plata ([1917] 1918): 262-282.

Panesi, Jorge. "Polémicas ocultas". Boletín 11 del Centro de Estudios de Teoría y Crítica Literaria (2003): 1-11. Web. 10 Dic. 2018. < http://www.celarg.org/int/arch publi/panesi polemicas ocultas.pdf $>$

Rojas, Ricardo. Cosmópolis. París: Garnier, 1908. - Los gauchescos. Historia de la literatura argentina. Ensayo filosófico sobre la evolución de la cultura en el Plata. Buenos Aires: Coni, 1917. I.

_. "Una mala palabra". Estudios. Academia Literaria del Plata (1918): 329-337.

- Los coloniales. Historia de la literatura argentina. Ensayo filosófico sobre la evolución de la cultura en el Plata. Buenos Aires: Losada, 1948. I.

. "Apéndice", Historia de la literatura argentina. Ensayo filosófico sobre la evolución de la cultura en el Plata. Los modernos. Buenos Aires: Kraft. 1957. II.

Salazar Anglada, Aníbal. “Julio Noé y La Antología de la poesía argentina moderna (1926): un punto de inflexión en la práctica antológica en Argentina”. Anales de Literatura Hispanoamericana 36 (2007):171-197.

Sarlo, Beatriz "Vanguardia y criollismo: la aventura del Martín Fierro". Altamirano, Carlos y Beatriz Sarlo. Ensayos Argentinos. De Sarmiento a la Vanguardia. Buenos Aires: Espasa-Calpe, [1983] 1997: 211-260. 
Schiffino, María Beatriz. "Ricardo Rojas y la invención de la literatura mestiza". Revista Pilquén 13. 14 (2011): 1-14.

Schvartzman, Julio. "Plumas gauchas". Cuadernos líricos 1 (2006): 61-75. Web. 01 Nov. 2018. < https://journals.openedition.org/lirico/798>

Sorensen, Diana. El Facundo y la construcción de la cultura argentina. César Aira (trad.). Rosario: Beatriz Viterbo, 1998.

Suriano, Juan. "Los festejos del primer Centenario de la Revolución de Mayo y la exclusión del movimiento obrero". Revista de Trabajo 6.8 (2010): 19-28. 